\title{
Topology Analysis of Chain Walking Polymerized Polyethylene: An Alternative Approach for the Branching Characterization by Thermal FFF
}

Martin Geisler, ${ }^{\dagger}$, William C. Smith, ${ }^{\S}$ Laura Plüschke, ${ }^{\dagger, \dagger}$ Robert Mundil,${ }^{\perp}$ Jan Merna,${ }^{\perp}$ S. Kim Ratanathanawongs Williams,${ }^{\S}$ and Albena Lederer*,†, ${ }^{*}$

'Polymer Separation Group, Leibniz-Institut für Polymerforschung Dresden e. V., Hohe Str. 6, 01069 Germany

*Faculty of Chemistry and Food Chemistry, Technische Universität Dresden, 01062 Dresden, Germany

${ }^{\S}$ Department of Chemistry, Colorado School of Mines, Golden, Colorado 80401, USA

$\perp$ Department of Polymers, University of Chemistry and Technology Prague, Technická 5, 16628 Praha 6, Czech Republic

*Email of corresponding author: lederer@ipfdd.de

Table of content for the Supplementary data:

1. Experimental Details $\quad S-2$

2. HT-SEC-D4 chromatograms and topological analysis $\quad \mathrm{S}-3$

3. Determination of the refractive index increment $d n d c^{-1}$ for cwPE S-4

4. Temperature dependent Dynamic Light scattering (DLS) experiments in batch S-4

5. ThFFF fractograms with online MALS, dRI and molar mass $\quad$ S-5

6. Dependency of $S_{\mathrm{T}}$ and $D_{\mathrm{T}}$ on the polymer topology (Fig. 3) from different $\Delta \mathrm{T}$ and $\tau$ S-6

7. Coefficients of the equations (9), (10) and (13) S-6

8. $\lambda^{-1}$ to $M_{\text {Seg }}, g$ versus $g^{\prime \prime}$ and the dependency of $t_{R}$ on B, each from different $\Delta \mathrm{T}$ and $\tau$ S-8

9. Numerical solution of Equation (7) to $\lambda \quad$ S-9

10. Development of equation (12) to be applied in equation (11) from the main article S-10

11. Cumulative and differential weight distributions of LCB and $g^{\prime \prime}$ S-11

$\begin{array}{ll}\text { 12. Uncertainties and errors } & \mathrm{S}-12\end{array}$

$\begin{array}{ll}\text { 13. References } & \text { S-14 }\end{array}$ 


\section{Experimental details}

\subsection{Materials}

The polyethylenes used in this work were synthesized with $\alpha$-diimine palladium catalyst ( [ $\left(\mathrm{N}, \mathrm{N}^{\prime}\right.$-bis(2,6diisopropylphenyl)-2,3-dimethyl-1,4-diazabutane) $\left.\mathrm{Pd}\left(\mathrm{CH}_{2}\right)_{3} \mathrm{COOCH}_{3}\right]^{+}\left[\mathrm{BAr}_{4}\right]^{-} \quad\left(\mathrm{Ar}^{\mathrm{F}}=3,5\right.$-bis-(trifluoromethyl)phenyl)) as described elsewhere ${ }^{1-3}$ based on the synthesis approach of Brookhart et al. ${ }^{4}$ with the conditions shown in Table S1. All samples contain 100 branches per 1000 total carbon atoms according to ${ }^{1} \mathrm{H}$ NMR analysis but differ in topology mainly influenced by ethene pressure. ${ }^{5}$

Table S1. Synthesis conditions, expected topology and the characterization average results of the investigated short chain branched cwPEs found by HT-SEC-D4.

\begin{tabular}{ccccc|ccc}
\hline \multicolumn{3}{c|}{ Synthesis conditions } & & \multicolumn{3}{c}{ Average results found by HT-SEC-D4 } \\
Sample $\mathrm{p} / \mathrm{bar}{ }^{\mathrm{a}} \mathrm{T} /{ }^{\circ} \mathrm{C}$ & $\begin{array}{c}\text { Reaction } \\
\text { time } / \mathrm{h}\end{array}$ & Expected topology & $M_{w} /$ & $R_{\mathrm{G}, z} / \mathrm{nm}$ & $v_{R}$ \\
\hline $\mathrm{hb} 1$ & 0.14 & 35 & 24 & highly branched, medium $M_{w}$ & $230 \pm 6$ & $15.8 \pm 0.3$ & $0.56 \pm 0.3$ \\
$\mathrm{hb} 2$ & 0.09 & 0 & 24 & highly branched, lower $M_{w}$ & $161.3 \pm 2.2$ & $12.9 \pm 0.2$ & 0.45 to $1.15^{*}$ \\
$\mathrm{~b} 1$ & 4 & 0 & 20 & linear, lower $M_{w}$ & $140 \pm 3$ & $16.6 \pm 0.4$ & $0.60 \pm 0.09$ \\
$\mathrm{~b} 2$ & 2 & 0 & 20 & branched, lower $M_{w}$ & $136 \pm 2$ & $16.3 \pm 0.2$ & $0.65 \pm 0.08$ \\
$\mathrm{sb}$ & 2 & 10 & 20 & slightly branched, higher $M_{w}$ & $313 \pm 8$ & $25.4 \pm 0.5$ & 0.47 to $0.73 *$ \\
lin1 & 8 & 0 & 20 & linear, lower $M_{w}$ & $175.4 \pm 0.5$ & $18.5 \pm 0.2$ & $0.53 \pm 0.02$ \\
$\operatorname{lin} 2$ & 8 & 10 & 20 & linear, higher $M_{w}$ & $384 \pm 7$ & $30.4 \pm 0.3$ & 0.35 to $0.74^{*}$ \\
\hline
\end{tabular}

Pd catalyst $10 \mu \mathrm{mol}$, chlorobenzene $30 \mathrm{~mL}$, ${ }^{\text {a absolute ethene pressure }}$

*) dependent on the molar mass, see Fig. S2

\subsection{Instrumentation}

\subsubsection{High temperature size exclusion chromatography}

High temperature quadruple-detector size exclusion chromatography (HT-SEC-D4) experiments were done with a PL-GPC220 (Polymer Laboratories Ltd., U. K.) setup, connected to a MALS detector (Wyatt Technology Corporation, USA), a dRI detector and an online viscometer (both Agilent Technologies, Inc., USA) as described in our previous report. ${ }^{2}$ The carrier fluid 1,2,4-trichlorobenzene was purchased from Sigma Aldrich with a purity of $\geq 99 \%$ and stabilized with $1 \mathrm{~g} \mathrm{~L}^{-1}$ 2,6-di-tert-butyl-4-methylphenol (Carl Roth, Germany, purity $\geq 98 \%$ ) to prevent thermo-oxidative decomposition. Data recording and analysis was done with the Astra ${ }^{\circledR}$ software, version 6.1.2.84 (Wyatt Technology Corporation, USA).

\subsubsection{Temperature dependent dynamic light scattering}

Temperature dependent dynamic light scattering (DLS) experiments were performed with a DynaPro® NanoStar ${ }^{\circledR}$ instrument $($ Laser $\lambda=658 \mathrm{~nm})$ by Wyatt Technology Corporation, USA using a $1.25 \mu 1$ quartz cuvette (total volume approximately $1 \mathrm{~mL}$ ). In all experiments, the cuvette was completely filled with ca. $0.8 \mathrm{~mL}$ sample solution to avoid cavities, containing $1 \mathrm{mg} \mathrm{mL}^{-1}$ of polymer, dissolved in cyclohexane (EMSURE®, Merck KGaA, Germany, purity $\geq 99.5 \%$ ) and filtered through a $0.45 \mu \mathrm{m}$ PTFE syringe filter (Carl Roth, Germany). The cuvette was closed with an affiliated PTFE lid and sealed with Parafilm® wax foil to prevent evaporation of solvent. The data recording and analysis was done with the software Dynamics ${ }^{\circledR}$ by Wyatt Technology Corporation, USA, versions 7.6.0.48 and 7.8.0.26 using the cumulant fit method. ${ }^{6}$ During the run of all experiments ( $\mathrm{T}=20$ to $60{ }^{\circ} \mathrm{C}$ in stages of $5 \mathrm{~K}$, total time ca. $6 \mathrm{~h}$ ) no solvent lost due to evaporation or leakage of the sealing was observed.

\subsubsection{ThFFF}

ThFFF experiments were carried out with a TF2000 set up, consisting of an isocratic pump, degasser, autosampler, actively heated and cooled ThFFF channel, PN3621 multi-angle light scattering (MALS) detector with a laser of the wavelength $532 \mathrm{~nm}$ and PN3150 differential refractive index (dRI) detector (all by Postnova Analytics $\mathrm{GmbH}$, Germany). The channel dimensions were $45.6 \mathrm{~cm}$ tip-to-tip length, width $2 \mathrm{~cm}$ and a thickness of $250 \mu \mathrm{m}$, realized by spacers made of Mylar $A \circledR$ and Teonex ${ }^{\circledR}$. All separations were done with a constant flow rate of $0.2 \mathrm{~mL} \mathrm{~min}^{-1}$ and CHX (EMSURE®, Merck KGaA, Germany, purity $\geq 99.5 \%$ ) as carrier fluid. The void time in all separations was $11.04 \mathrm{~min}$. A channel pressure of about $1 \mathrm{MPa}$ to avoid boiling of the carrier fluid at the hot wall was adjusted for the used flow rate by a sufficient long back pressure tubing (inner diameter $0.001^{\prime \prime}$ ) between the ThFFF channel and the MALS detector. The data recording and analysis was carried out with the Postnova software. 


\section{HT-SEC-D4 chromatograms and topological analysis}

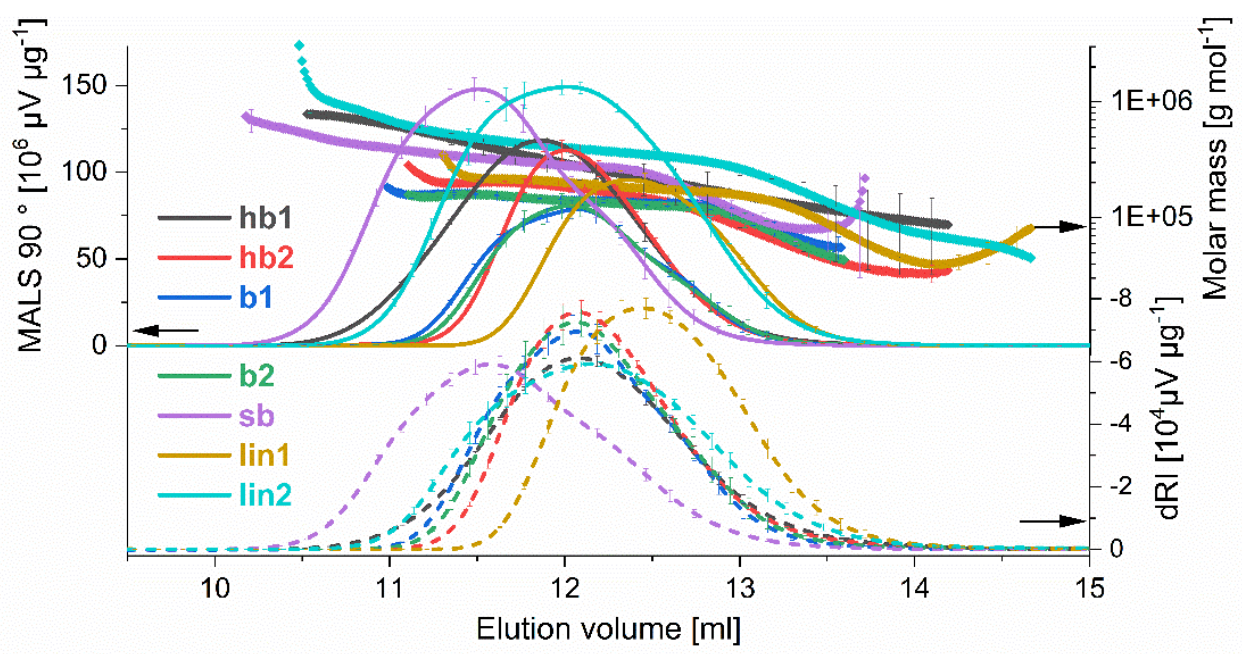

Figure S1. Superimposed HT-SEC-D4 chromatograms of 7 short chain branched chain walk polyethylenes (cwPE) with different topologies ranging from linear up to hyperbranched macrostructure, measured at $150{ }^{\circ} \mathrm{C}$ in 1,2,4-trichlorobenzene as eluent. The flow rate was $1 \mathrm{~mL} \mathrm{~min}^{-1}$.
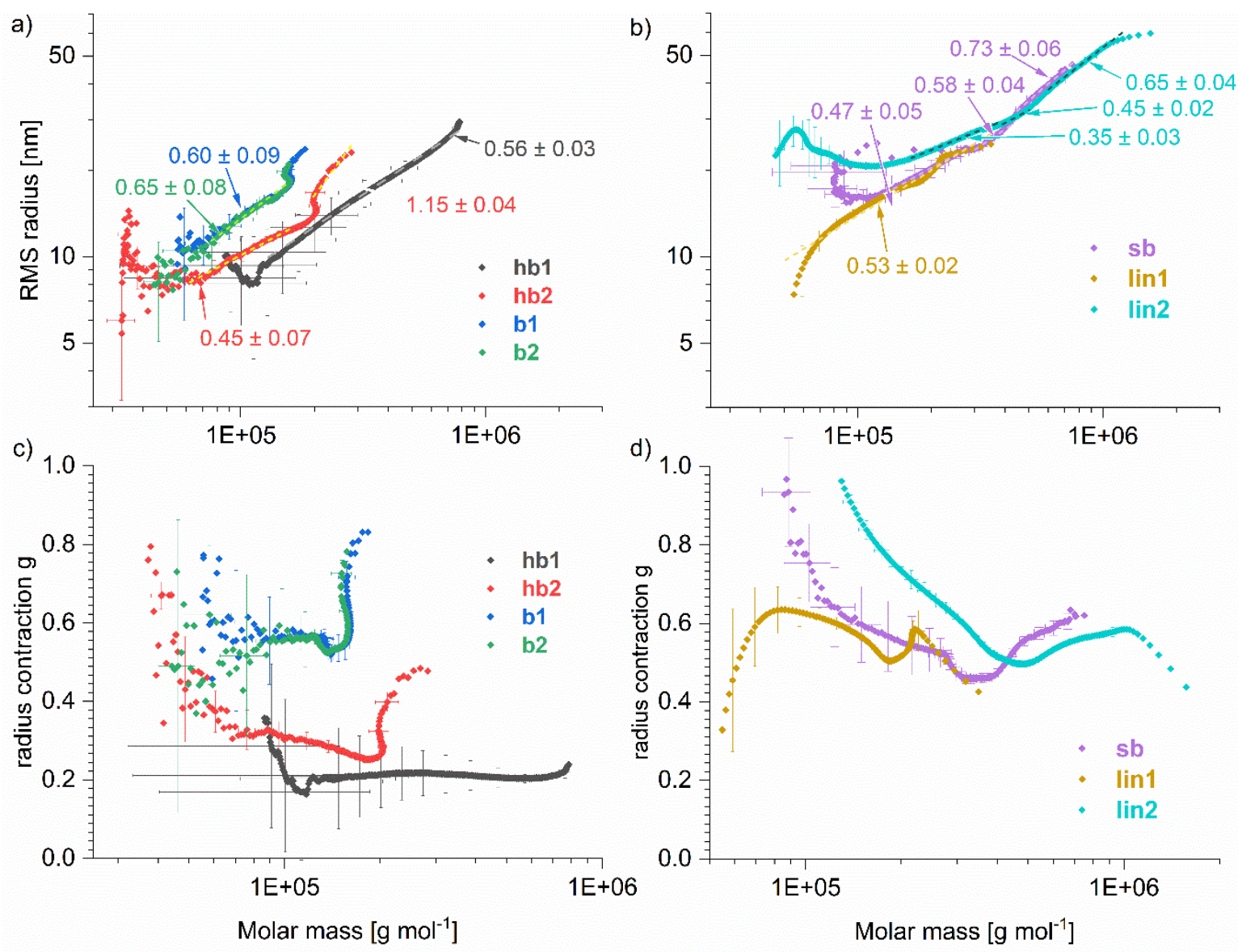

Figure S2. Superimposed conformation plots ( $a$ and $b$ ) of the cwPE from Fig. S1 and the radius contraction factors (c and d), calculated with the linear model $R_{\mathrm{G}, \mathrm{LIN}}=0.023 M^{0.58}$.

Generally, polymers of the same topology show a scaling behavior described by the relation $R_{\mathrm{G}}=K \cdot M^{v_{R}}$ where $K$ is a polymer specific constant and $v_{R}$ is the scaling exponent describing the conformation of the polymer. Analogue to this, the so-called Kuhn-Mark-Houwink-Sakurada Equation $[\eta]=K \cdot M^{\alpha}$ can be used. Theoretical values for $v$ are in the range from 0.33 representing a compact sphere passing through 0.59 for a random linear coil in a thermodynamically good solvent up to 1 for rigid rods. ${ }^{7-9}$ For $\alpha$ instead, the value range is broader starting from 0 for very compact object, passing 1.0 for linear coils in a good solvent up to 2 for rod-like objects. ${ }^{8-10}$ 


\section{Determination of the Refractive Index Increment for cwPE}
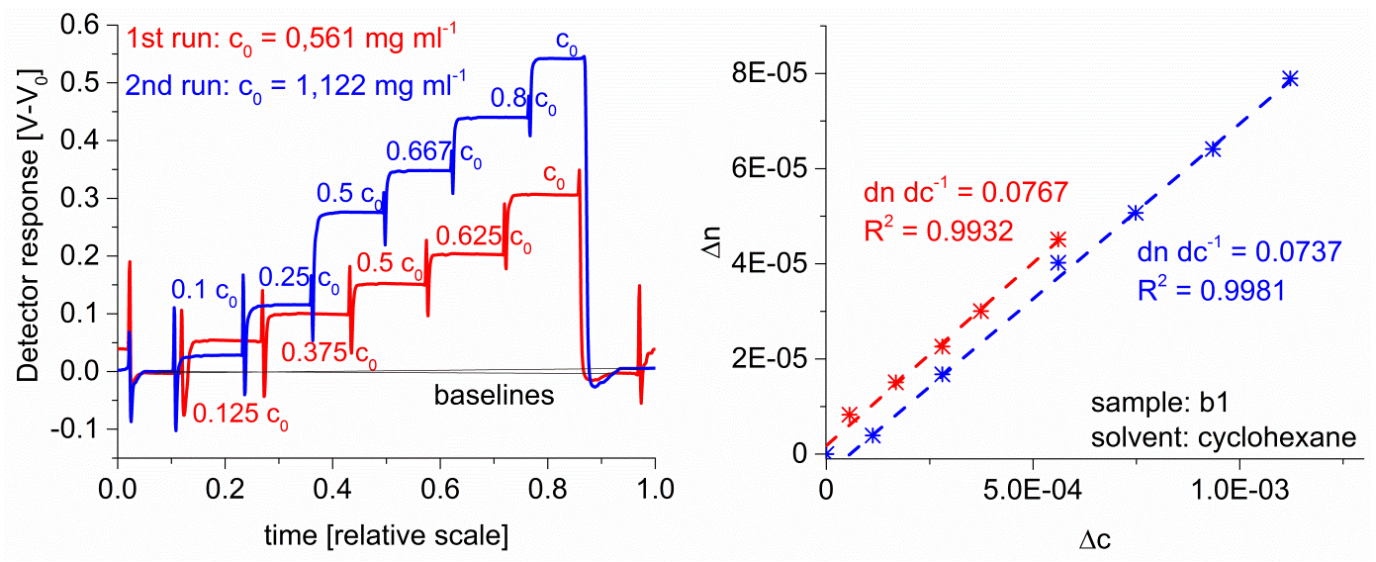

Figure S3. The determination of the refractive index increment $d n d c^{-1}$ of cwPE, represented by sample b1, gave an average $d n d c^{-1}=0.0752 \pm 0.0015 \mathrm{~mL} \mathrm{~g}^{-1}$. Changes in the $d n d c^{-1}$ caused by molar mass and topology differences are assumed to be negligible.

\section{Temperature dependent Dynamic Light scattering (DLS) experiments in batch}

a) $\overline{i n}_{\text {is }}$

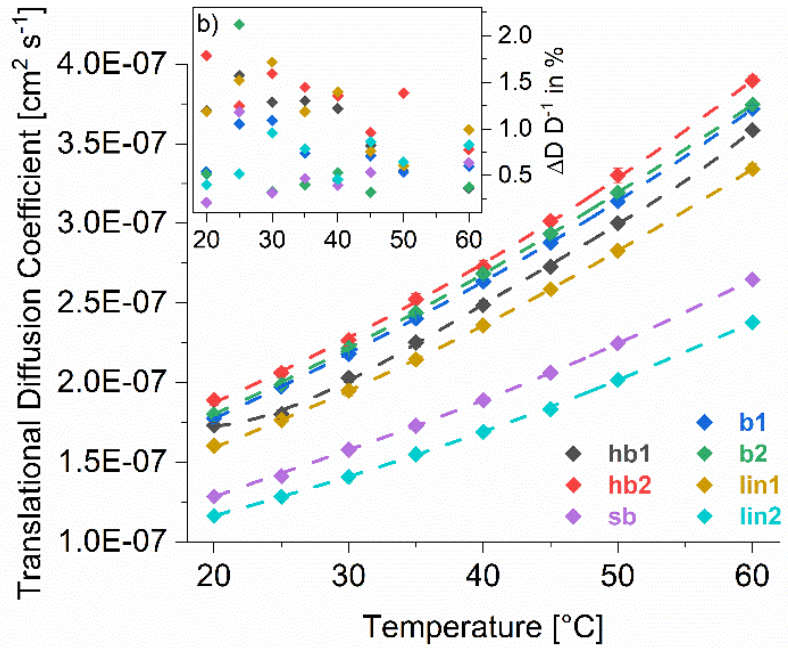

c)

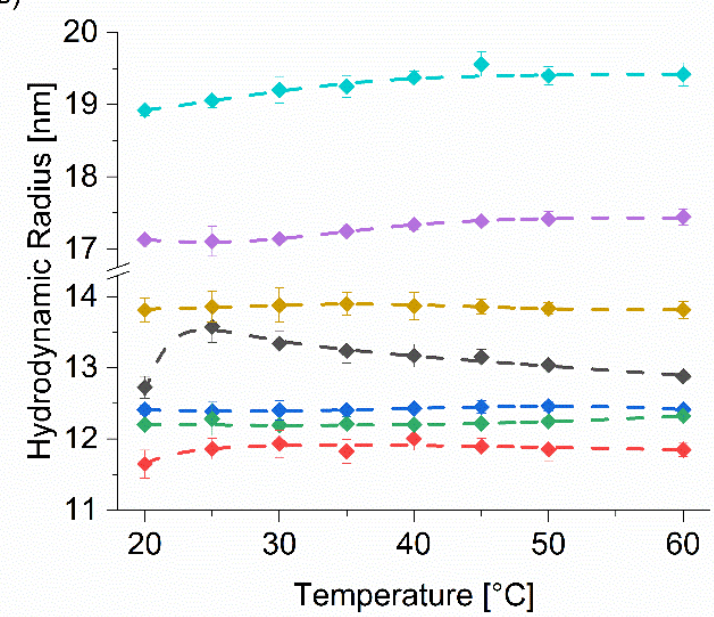

Figure S4. Superimposed translational diffusion coefficients (a) with their relative uncertainties in inset (b) and the hydrodynamic radii (c) of the cwPE with different topologies, dissolved in cyclohexane with a concentration of $1 \mathrm{~g} \mathrm{~L}^{-1}$. The data were obtained by temperature dependent DLS experiments in batch.

The hydrodynamic radius $R_{\mathrm{h}}$ represents the radius of an equivalent hard sphere with the same diffusion rate. It can be calculated from the translational diffusion coefficient $D$ by the Stokes-Einstein-relationship ${ }^{9,11}$

$$
R_{\mathrm{h}}=\frac{k_{B} \cdot T}{6 \pi \cdot \eta \cdot D}
$$

where $k_{B}$ is the Boltzmann constant, $\mathrm{T}$ is here the absolute temperature in $[\mathrm{K}], \eta$ is the dynamic viscosity of the solvent at the same temperature.

$D$-fits as illustrated in Fig. S4; used in this work for the calculation of $D_{\mathrm{T}}\left[\mathrm{T}\right.$ in $\left.{ }^{\circ} \mathrm{C}\right]$ :

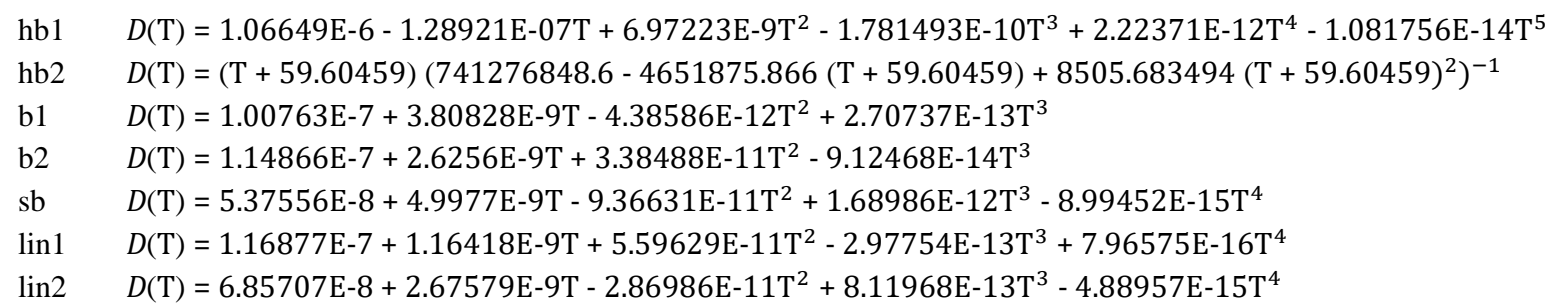




\section{ThFFF fractograms with online MALS, dRI and molar mass}
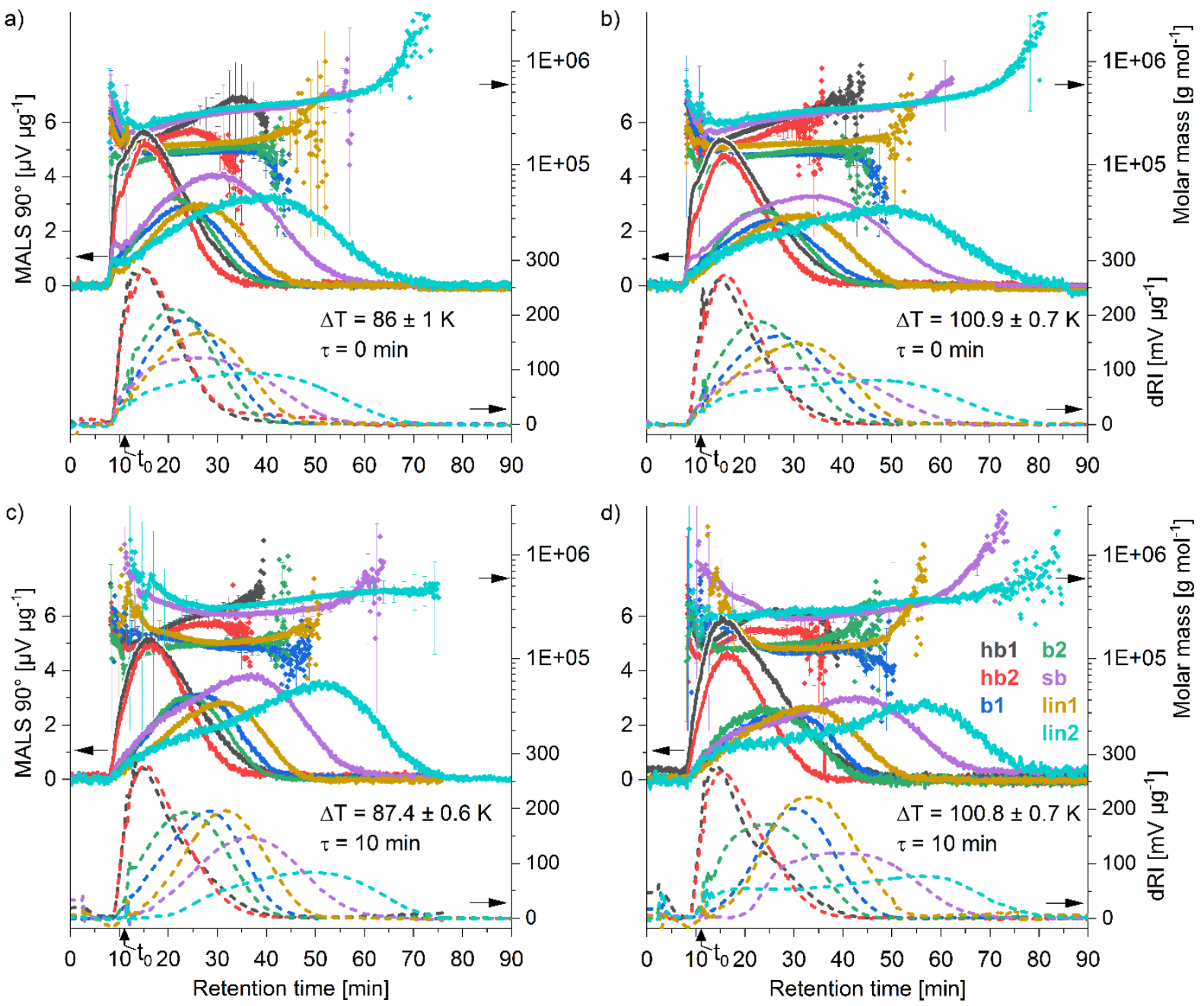

Figure S5. Superimposed fractograms of seven short chain branched chain walk polyethylenes (cwPE) with different topologies ranging from linear up to hyperbranched macrostructure, separated without stop-flow (a and b) and with stop-flow of $\tau=10 \mathrm{~min}$ (c and d), each with 2 different field strengths of $\Delta \mathrm{T} \approx 85 \mathrm{~K}$ and $\Delta \mathrm{T} \approx 100 \mathrm{~K}$. The void time corresponding to the used flow rate of $0.2 \mathrm{ml} \mathrm{min}^{-1}$ was $t_{0}=11.035 \mathrm{~min}$.

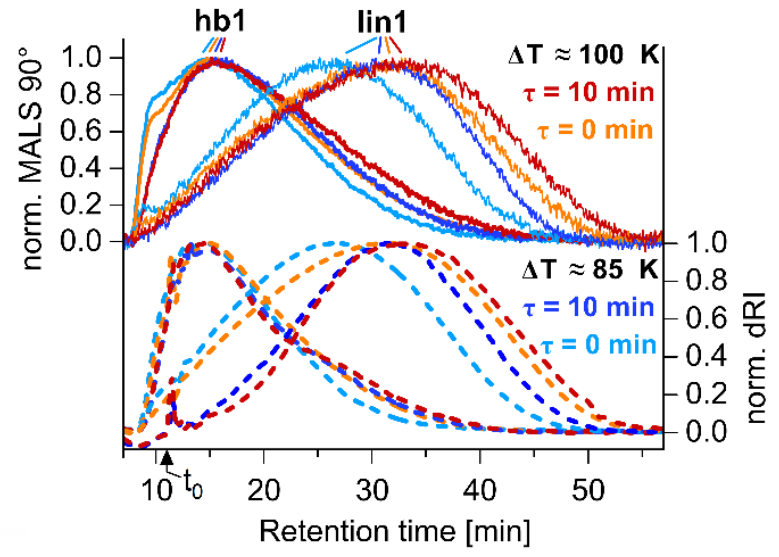

Figure S6. Different topologies of about the same molar mass showed differences in their mean retention time, indicating a different duration to reach their relaxation equilibrium: The found mean retention times between $\Delta \mathrm{T} \approx 85 \mathrm{~K}$ and $\Delta \mathrm{T} \approx 100 \mathrm{~K}$ measured without stop-flow show a significantly larger difference than the experiments with a stop-flow of $\tau=10 \mathrm{~min}$. 


\section{Dependency of $S_{\mathrm{T}}$ and $D_{\mathrm{T}}$ on the polymer topology (Fig. 3) from different $\Delta \mathrm{T}$ and $\tau$}
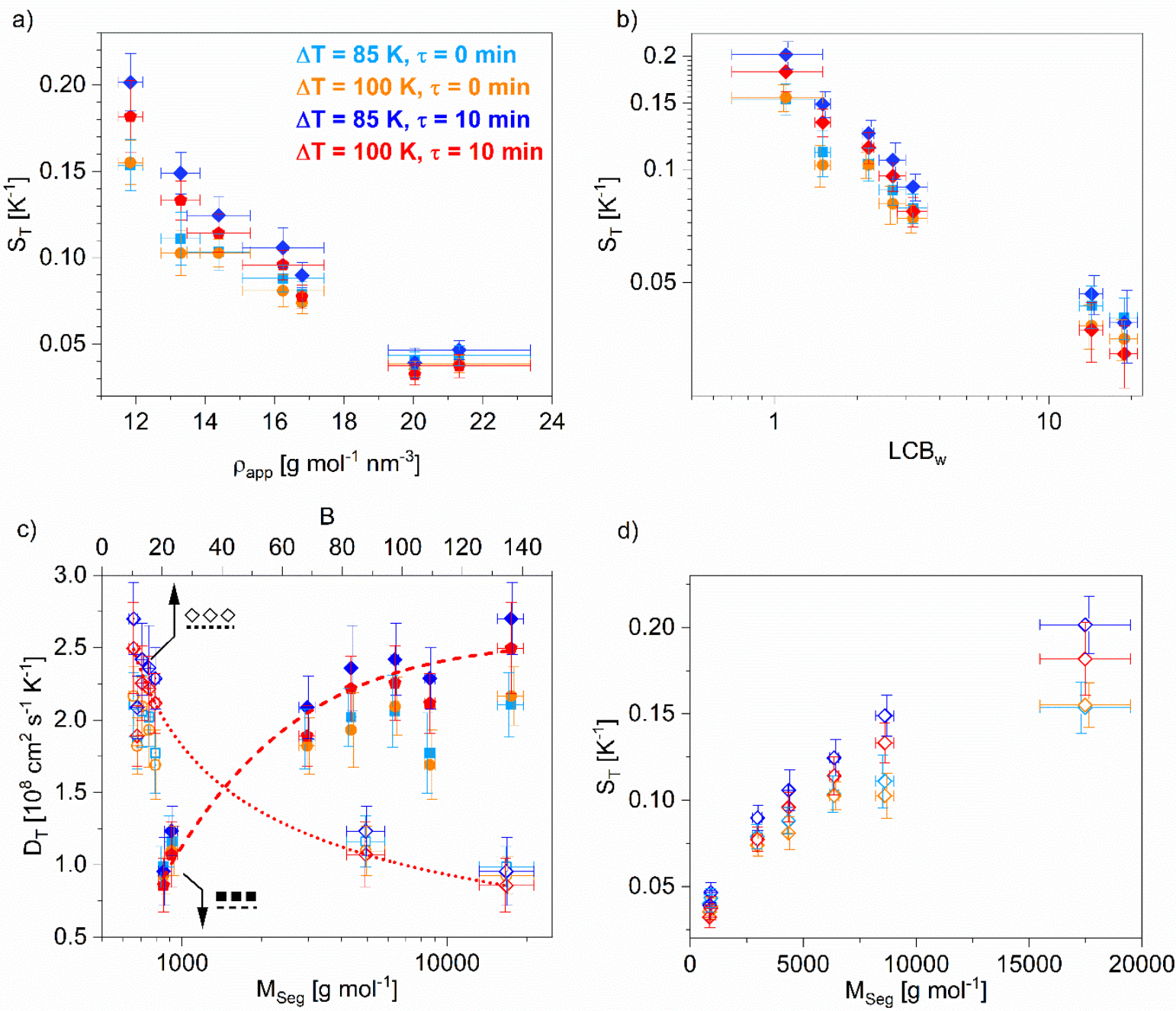

Figure S7. The dependency of $S_{\mathrm{T}}$ and $D_{\mathrm{T}}$ on the polymer topology: a) $S_{\mathrm{T}}$ vs. $\rho_{a p p}$; b) $S_{\mathrm{T}}$ vs. $L C B_{w} ;$ c) $D_{\mathrm{T}} \mathrm{vs.} B, M_{S e g}$ and d) $S_{\mathrm{T}}$ vs. $M_{\text {seg. }}$. All branching parameters were calculated from HT-SEC-D4 data and temperature-dependent DLS data (measured in batch). The dotted and dashed red lines are fits for guiding the eye for $\Delta \mathrm{T}=100 \mathrm{~K}, \tau=10 \mathrm{~min}$.

The molecular apparent density $\rho_{a p p},{ }^{12}$ shown in (a) was calculated by the definition

$$
\rho_{a p p}=\frac{3 M}{4 \pi R^{3}}
$$

where $R$ is the equivalent sphere radius, for the original definition derived from its dependence to $[\eta] .{ }^{13}$ Here, we used the hydrodynamic radius $R_{\mathrm{h}}$ derived from DLS experiments calculated from $D$ by the Stokes-Einstein equation..$^{9,11}$

\section{Coefficients of the equations (9), (10) and (13) in the main article}

\section{Equation (9):}

$$
S_{\mathrm{T}, \mathrm{LIN}}=\frac{\left(a_{1} \cdot \Delta \mathrm{T}+a_{2}\right) \cdot \ln M_{w}-\left(a_{3} \cdot \Delta \mathrm{T}+a_{4}\right)}{\Delta \mathrm{T}}\left[\mathrm{K}^{-1}\right]
$$

Table S2 The coefficients used in equation (9)

\begin{tabular}{lcc}
\hline & $\tau=0 \min$ & $\tau=10 \min$ \\
\hline$a_{1}$ & 0.04365228 & 0.02443976 \\
$a_{2}$ & -0.75990437 & 2.16415169 \\
$a_{3}$ & 0.29717323 & 0.17378145 \\
$a_{4}$ & -8.55297743 & 10.8069849 \\
\hline
\end{tabular}


Equation (10):

$$
g\left(g^{\prime \prime}\right)=K_{1}+\left(K_{2}-K_{1}\right)\left[\frac{K_{3}}{1+10^{\left(K_{4}-g^{\prime \prime}\right) K_{5}}}+\frac{1-K_{3}}{1+10^{\left(K_{6}-g^{\prime \prime}\right) K_{7}}}\right]
$$

Table S3-1 K-coefficients of equation (10)(13):

\begin{tabular}{l|cc}
\hline$K$ coefficients & $\tau=0 \min$ & $\tau=10 \min$ \\
\hline$K_{1}$ & $c_{1} \cdot \Delta T^{2}+c_{2} \cdot \Delta T+c_{3}$ & $c_{1} \cdot \Delta T^{2}+c_{2} \cdot \Delta T+c_{3}$ \\
$K_{2}$ & $c_{4} \cdot \Delta T+c_{5}$ & $c_{4} \cdot \Delta T^{2}+c_{5} \cdot \Delta T+c_{6}$ \\
$K_{3}$ & $c_{6} \cdot \Delta T+c_{7}$ & $c_{7} \cdot \Delta T^{2}+c_{8} \cdot \Delta T+c_{9}$ \\
$K_{4}$ & $c_{8} \cdot \Delta T+c_{9}$ & $c_{10} \cdot \Delta T^{2}+c_{11} \cdot \Delta T+c_{12}$ \\
$K_{5}$ & $c_{10}+c_{11} \cdot c_{12} \Delta T$ & $c_{13} \cdot \Delta T^{2}+c_{14} \cdot \Delta T+c_{15}$ \\
$K_{6}$ & $c_{13} \cdot \Delta T^{2}+c_{14} \cdot \Delta T+c_{15}$ & $c_{16} \cdot \Delta T^{2}+c_{17} \cdot \Delta T+c_{18}$ \\
$K_{7}$ & $c_{16}+c_{17} \cdot e^{c_{18} \cdot \Delta T}$ & $c_{19} \cdot \Delta T^{2}+c_{20} \cdot \Delta T+c_{21}$ \\
\hline
\end{tabular}

Table S3-2 c-coefficients of equation (10)(13):

\begin{tabular}{c|ccccc}
\hline$c$ coefficients & $\tau=0 \mathrm{~min}$ & $\tau=10 \mathrm{~min}$ & $c$ coefficients & $\tau=0 \mathrm{~min}$ & $\tau=10 \mathrm{~min}$ \\
\hline$c_{1}$ & $1.03514 \mathrm{E}-04$ & $3.56288 \mathrm{E}-03$ & $c_{12}$ & 0.734959533 & 9.208338 \\
$c_{2}$ & -0.02400594 & -0.6782382 & $c_{13}$ & $-3.517549 \mathrm{E}-05$ & $5.636435 \mathrm{E}-03$ \\
$c_{3}$ & 1.195496 & 31.64408 & $c_{14}$ & $4.30501 \mathrm{E}-03$ & -1.05332 \\
$c_{4}$ & -0.01279948 & $-1.030309 \mathrm{E}-03$ & $c_{15}$ & 1.023378 & 52.2233 \\
$c_{5}$ & 3.278437 & 0.1894345 & $c_{16}$ & 3.136567757 & $-1.070268 \mathrm{E}-04$ \\
$c_{6}$ & $3.314146 \mathrm{E}-03$ & -6.636798 & $c_{17}$ & $6.00572485 \mathrm{E}-06$ & 0.01883061 \\
$c_{7}$ & $8.183203 \mathrm{E}-03$ & $-5.771928 \mathrm{E}-04$ & $c_{18}$ & 0.109717763 & 0.2853224 \\
$c_{8}$ & $-3.215138 \mathrm{E}-03$ & 0.1110859 & $c_{19}$ & & $1.408593 \mathrm{E}-03$ \\
$c_{9}$ & 0.4663463 & -4.904675 & $c_{20}$ & & -0.2466364 \\
$c_{10}$ & 3.578675501 & $1.013327 \mathrm{E}-03$ & $c_{21}$ & & 14.08777 \\
$c_{11}$ & $8.19243552 \mathrm{E}+10$ & -0.1934036 & & & \\
\hline
\end{tabular}

Equation (13):(13)

$$
B_{\text {apex }}\left(R_{\text {apex }}\right)=K_{1}+\frac{K_{2}-K_{1}}{\left[1+\left(K_{3} / R\right)^{K_{4}}\right]^{K_{5}}}
$$

Table S4-1 K-coefficients of equation (13)(13):

\begin{tabular}{l|cc}
\hline$K$ coefficients & $\tau=0 \min$ & $\tau=10 \mathrm{~min}$ \\
\hline$K_{1}$ & $c_{1} \cdot \Delta \mathrm{T}^{2}+c_{2} \cdot \Delta \mathrm{T}+c_{3}$ & $c_{1} \cdot \Delta \mathrm{T}+c_{2}$ \\
$K_{2}$ & $c_{4} \cdot \Delta \mathrm{T}^{2}+c_{5} \cdot \Delta \mathrm{T}+c_{6}$ & $c_{3} \cdot \Delta \mathrm{T}+c_{4}$ \\
$K_{3}$ & $c_{7} \cdot \Delta \mathrm{T}+c_{8}$ & $c_{5} \cdot \Delta \mathrm{T}^{2}+c_{6} \cdot \Delta \mathrm{T}+c_{7}$ \\
$K_{4}$ & $c_{9} \cdot \Delta \mathrm{T}^{2}+c_{10} \cdot \Delta \mathrm{T}+c_{11}$ & $c_{8} \cdot \Delta \mathrm{T}^{2}+c_{9} \cdot \Delta \mathrm{T}+c_{10}$ \\
$K_{5}$ & $c_{12} \cdot \Delta \mathrm{T}^{c_{13}}$ & $c_{11}+c_{12} \cdot e^{c_{13} \cdot \Delta \mathrm{T}}$ \\
\hline
\end{tabular}

Table S4-2 c-coefficients of equation (13)(13):

\begin{tabular}{l|cclcc}
\hline$c$ coefficients & $\tau=0$ min & $\tau=10 \mathrm{~min}$ & $c$ coefficients & $\tau=0$ min & $\tau=10 \mathrm{~min}$ \\
\hline$c_{1}$ & $1.718121 \mathrm{E}-04$ & -0.02596673 & $c_{8}$ & -0.253226 & $1.99612 \mathrm{E}-04$ \\
$c_{2}$ & 0.03441019 & 14.37017 & $c_{9}$ & $7.798888 \mathrm{E}-04$ & -0.04425696 \\
$c_{3}$ & 10.60227 & 1.676767 & $c_{10}$ & -0.1723634 & 5.409786 \\
$c_{4}$ & 0.9175371 & 45.63905 & $c_{11}$ & 13.44938 & 10.00016233 \\
$c_{5}$ & -143.7393 & $3.764237 \mathrm{E}-05$ & $c_{12}$ & 236.6771 & $-2.23036533 \mathrm{E}-19$ \\
$c_{6}$ & 5886.537 & $-7.257181 \mathrm{E}-03$ & $c_{13}$ & -1.056082 & 0.411955132 \\
$c_{7}$ & 0.01120072 & 0.6693172 & & & \\
\hline
\end{tabular}


8. $\lambda^{-1}$ vs. $M_{S e g}, g$ vs. $g^{\text {" }}$ and the dependency of $t_{R}$ on B, each from different $\Delta \mathrm{T}$ and $\tau$
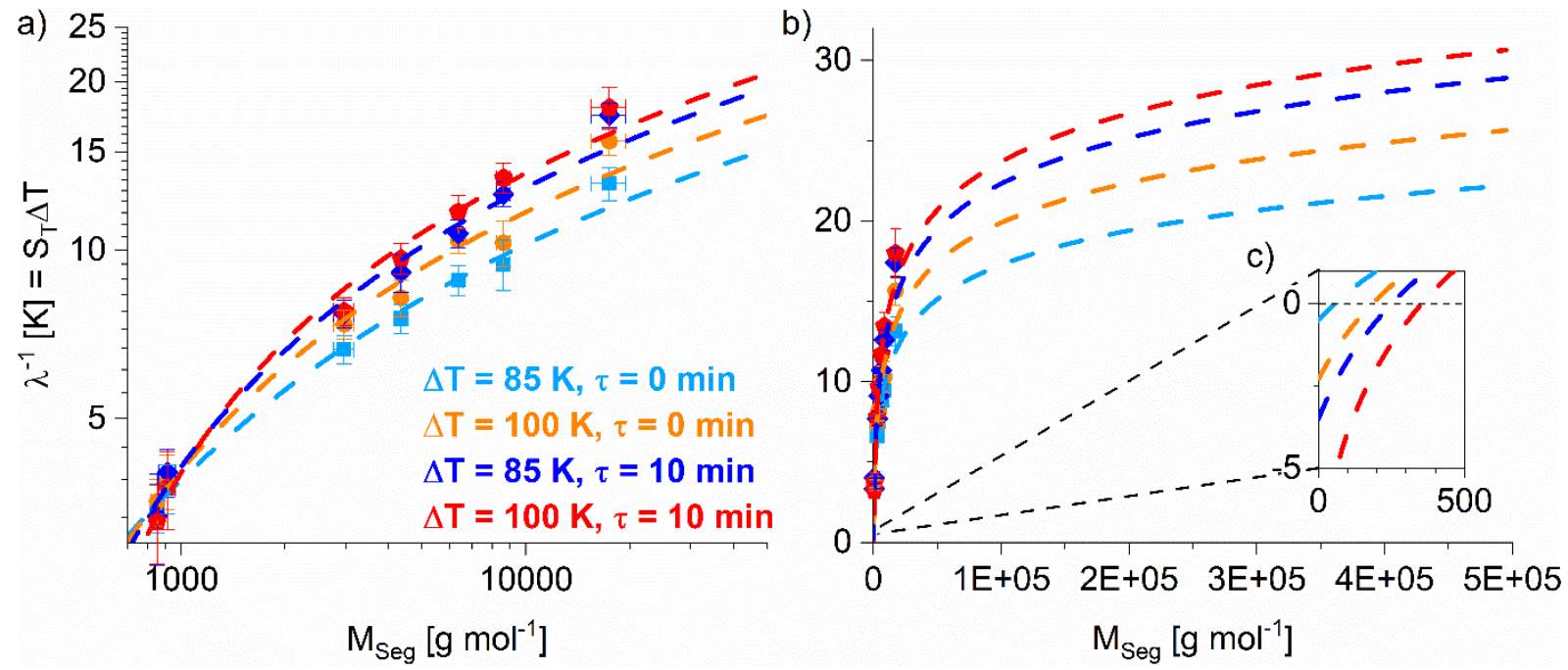

Figure S8. Double logarithmic plot of $\lambda^{-1}$ against $M_{\text {seg }}$ in four different experimental conditions, fitted with a natural logarithmic function $y=a \ln (x)+b$. b) shows the continuation of the fits to $M_{w}$ and the inset in (b) indicates the trend to negative $S_{\mathrm{T}}$ values for $M_{\text {seg }}$ in the molar mass range of n-alkanes.
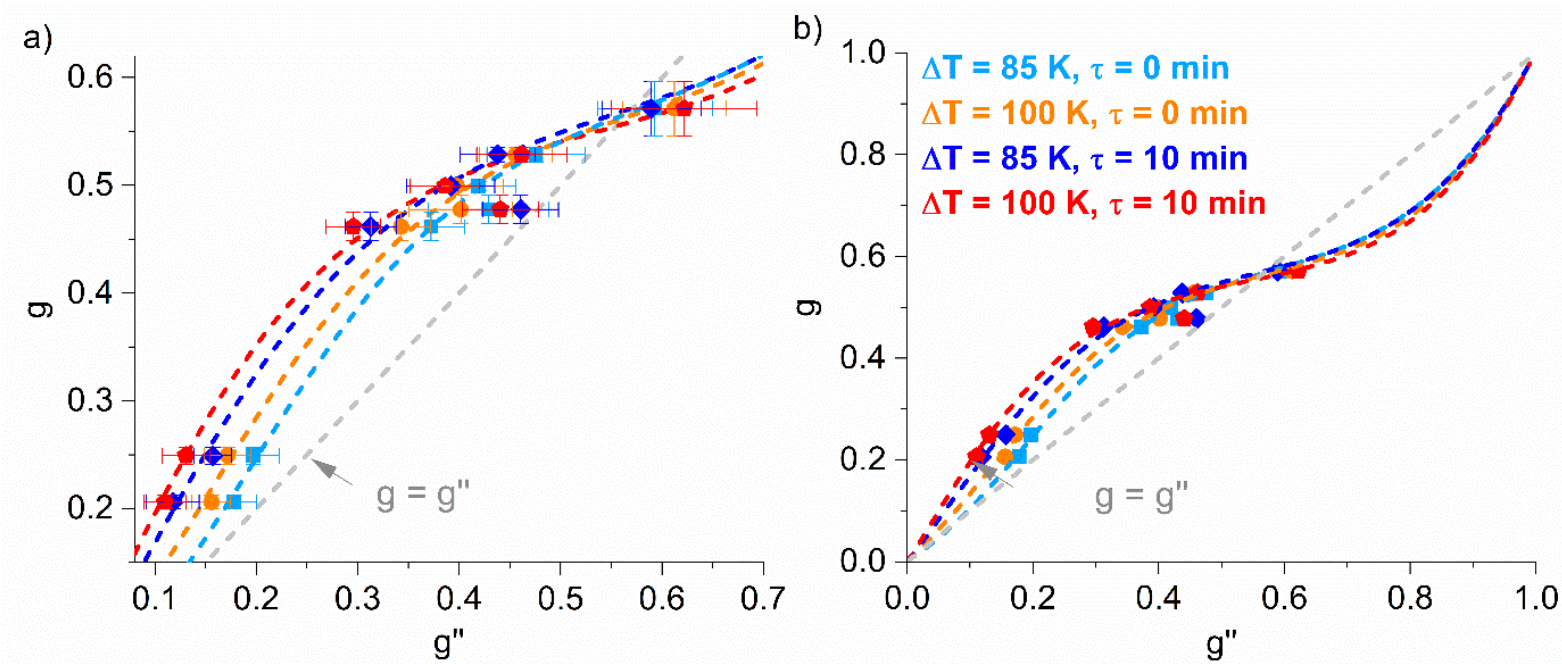

Figure S9. a) The comparison of $g$ and $g^{\prime \prime}$ and the fit to transform $g$ " into $g$ for further calculations for $\Delta \mathrm{T}=85 \mathrm{~K}$ and $100 \mathrm{~K}$, each field strength un-/partially relaxed $(\tau=0 \mathrm{~min})$ and fully relaxed $(\tau=10 \mathrm{~min})$. The plot (b) shows the plot (a) in the full scale within the limits of 0 and 1 for the fit in Eq. (10) in the main article.

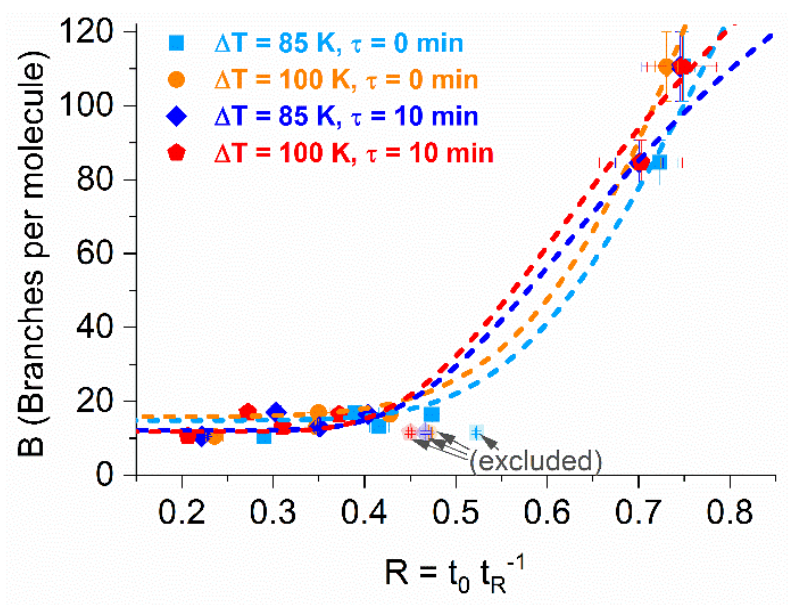

Figure S10. The dependency of the mean retention time $t_{R}$ on the number of branches per molecule, measured with two different field strengths, each as un-/partially and as fully relaxed system. The dashed lines indicate the mathematical fit with Eq. (13) in the main article. 


\section{Numerical solution of Equation (7) from the main article for $\lambda$}

$R=6 \lambda\left[v+(1-6 \lambda v)\left(\operatorname{coth}\left(\frac{1}{2 \lambda}\right)-2 \lambda\right)\right]$

$\lambda=\left(K_{0}+K_{1} \cdot \sqrt[3]{R}+K_{2} \cdot \sqrt[3]{R}^{2}+K_{3} \cdot \sqrt[3]{R}^{3}+K_{4} \cdot \sqrt[3]{R}^{4}+K_{5} \cdot \sqrt[3]{R}^{5}+K_{6} \cdot \sqrt[3]{R}^{6}+K_{7} \cdot \sqrt[3]{R}^{7}\right)^{-1}$

with $K_{x}=(\ldots)_{0}+(\ldots)_{1} \cdot v+(\ldots)_{2} \cdot v^{2}+(\ldots)_{3} \cdot v^{3}+(\ldots)_{4} \cdot v^{4} \quad(x=1 \ldots 7)$

Non-parabolicity coefficient $v$ of the flow profile: ${ }^{14} \quad v=\left(a_{1} \cdot \mathrm{T}_{c}+a_{2}\right) \cdot \Delta \mathrm{T}+\left(a_{3} \cdot \mathrm{T}_{c}+a_{4}\right) \cdot \Delta \mathrm{T}^{2}+\left(a_{5} \cdot \mathrm{T}_{c}+a_{6}\right) \cdot \Delta \mathrm{T}^{3}$

with $\mathrm{a}_{1}$ to $\mathrm{a}_{6}$ see Ref. ${ }^{14} ; \mathrm{T}_{\mathrm{c}}$ is the cold wall temperature

Coefficients:

$K_{0}$ with $b_{0}$ to $b_{4}: K_{0}=b_{0}+b_{1} \cdot v+b_{2} \cdot v^{2}+b_{3} \cdot v^{3}+b_{4} \cdot v^{4}$

$K_{1}: c_{0}$ to $c_{4} ; \quad K_{2}: d_{0}$ to $d_{4} ; \quad K_{3}: e_{0}$ to $e_{4} ; \quad K_{4}: f_{0}$ to $f_{4} ; \quad K_{5}: g_{0}$ to $g_{4} ; \quad K_{6}: h_{0}$ to $h_{4} ; \quad K_{7}: i_{0}$ to $i_{4}$

Table S5 coefficients for $K_{x}$

\begin{tabular}{cccccc}
\hline & $(\ldots)_{0}$ & $(\ldots)_{1}$ & $(\ldots)_{2}$ & $(\ldots)_{3}$ & $(\ldots)_{4}$ \\
\hline$b_{x}$ & 4228.278546 & 7408.974837 & 14058.75949 & 18774.62229 & 9786.035969 \\
$c_{X}$ & -38661.16221 & -74509.45542 & -153780.2465 & -197891.3378 & -100549.6353 \\
$d_{x}$ & 158631.4997 & 328855.2611 & 709355.5714 & 879493.7253 & 436446.678 \\
$e_{X}$ & -369963.6997 & -811709.8986 & -1788451.305 & -2136892.459 & -1035884.973 \\
$f_{x}$ & 523121.7591 & 1199855.428 & 2662459.885 & 3066184.996 & 1451155.933 \\
$g_{x}$ & -445233.8718 & -1057390.797 & -2341292.672 & -2599225.546 & -1199935.406 \\
$h_{x}$ & 210269.538 & 513123.7367 & 1126627.035 & 1205908.256 & 542453.3103 \\
$i_{x}$ & -42392.08074 & -105632.055 & -228974.412 & -236348.7758 & -103470.0162 \\
\hline
\end{tabular}

Ranges of precision:

$v$

0 to -0.1343

-0.1343 to -0.1937

$\mathbf{- 0 . 1 9 3 7}$ to $\mathbf{- 0 . 4 5 8 3}$

-0.4583 to -0.4821

-0.4821 to -0.5247
$\Delta R R^{-1}$

$100 \%$ for $R<1.2$

$\leq 26 \%$ for $R<1.2$

$\leq 1 \%$ for $R<1.2$

$\leq 10 \%$ for $R<1.2$

$<65 \%$ for $R<1.2$ exemplary for Cyclohexane:

$\Delta \mathrm{T} \quad \mathrm{T}_{\mathrm{c}}$

0 to $25 \mathrm{~K}$

17.47 to $18.84{ }^{\circ} \mathrm{C}$

$\leq 17 \%$ for $R>1.2$

25 to $40 \mathrm{~K}$

40 to $130 \mathrm{~K}$

130 to $140 \mathrm{~K}$

140 to $160 \mathrm{~K}$
18.84 to $21^{\circ} \mathrm{C}$

$21^{\circ} \mathrm{C}$

$21.3{ }^{\circ} \mathrm{C}$

21.3 to $25.3{ }^{\circ} \mathrm{C}$ a)

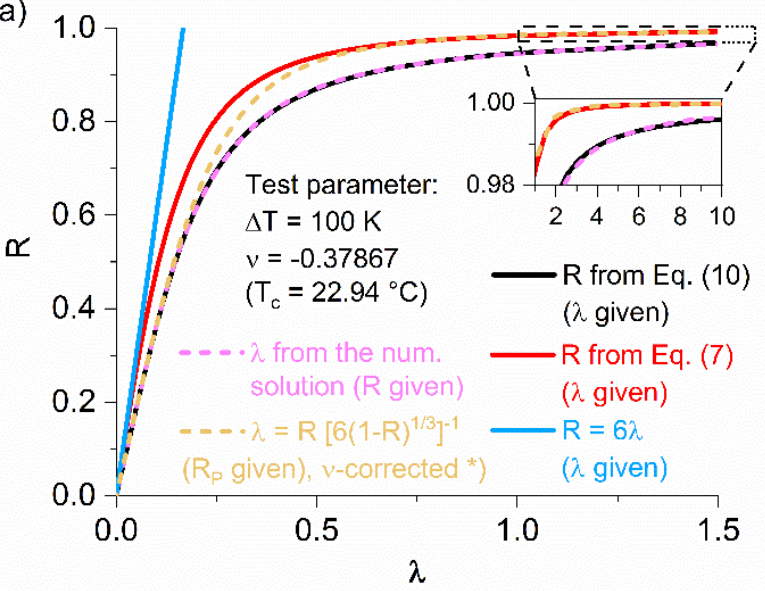

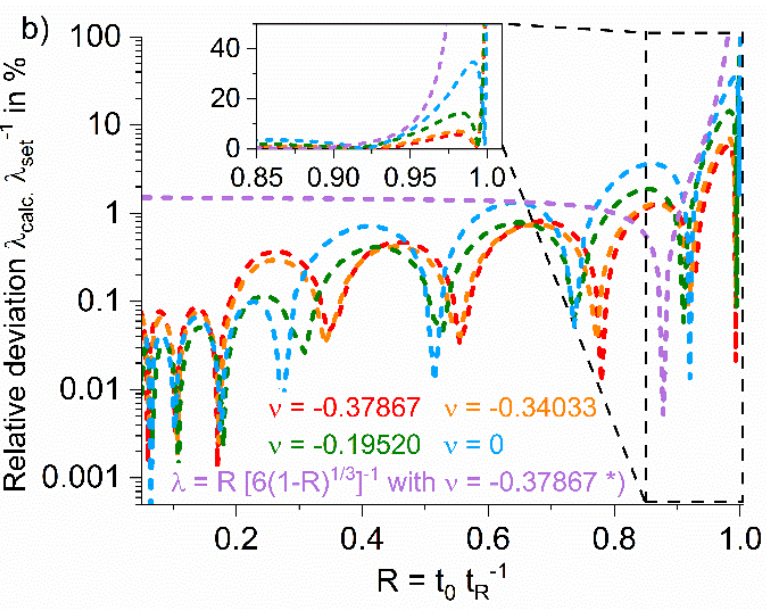

Figure S11. Recursive test of the numeric model (a) with the exact solution of $R$ (black; $\lambda$ solved by computation to exact match with a residual uncertainty of $1 \mathrm{E}-9) ; R$ recalculated by Equation (7) with the numerically calc. $\lambda$ in in comparison to the simplified relations (red and blue) for $R$ widely used in the literature. $\mathrm{b}$ ) The residual deviation of $R$ calc. by the numeric model for $\lambda$ along the retention time exemplary for 4 different conditions within the range of validity for the model. Especially for poor retention with a certain field strength a more precise calculation of $\lambda$ could be achieved, compared to the solution suggested by Schure, Schimpf and Schettler. ${ }^{15}$

*) corrected by $v$ with $R=6 \lambda v\left(1-R_{\text {Parabolic }}\right)+R_{\text {Parabolic. }}{ }^{16}$ The average retention time (dRI peak apex) for all samples analysed in this work leads to $\mathrm{R}$ values below 0.8 representing less than $1.5 \%$ error in lambda, with error increasing as $\mathrm{R}$ approaches 1 . 
10. Development of equation (12) to be applied in equation (11) from the main article, $g^{\prime \prime}$ from peak apex to $g^{\prime \prime}\left(t_{R}\right)$ for the entire fractogram:

$$
g^{\prime \prime}{ }_{i}(R)=\left[\frac{S_{\mathrm{T}, \mathrm{BRA}}\left(M_{S e g, i}\right)}{S_{\mathrm{T}, \mathrm{LIN}}\left(M_{i}\right)}\right]_{M_{i}}
$$

$$
\text { with } M_{S e g, i}(R) \approx \frac{M_{i}(R)}{2 B_{\text {apex }}+1}
$$

$L C B_{i, \text { ThFFF }}\left[g_{i}\right.$ from $\left.g^{\prime \prime}{ }_{i}(R)\right]$ was found to be in good agreement for $R_{\text {apex }}<<1$. However, for poorly retained analytes a correction is needed.

Boundary conditions:

Empirically found for poor retention values

$M_{\text {Seg }, i}\left(R_{\text {apex }}=0.78\right)=\frac{0.8 \cdot M_{\text {apex }}+0.2 \cdot M_{i}(R)}{1.6 \cdot B_{\text {apex }}+1}$

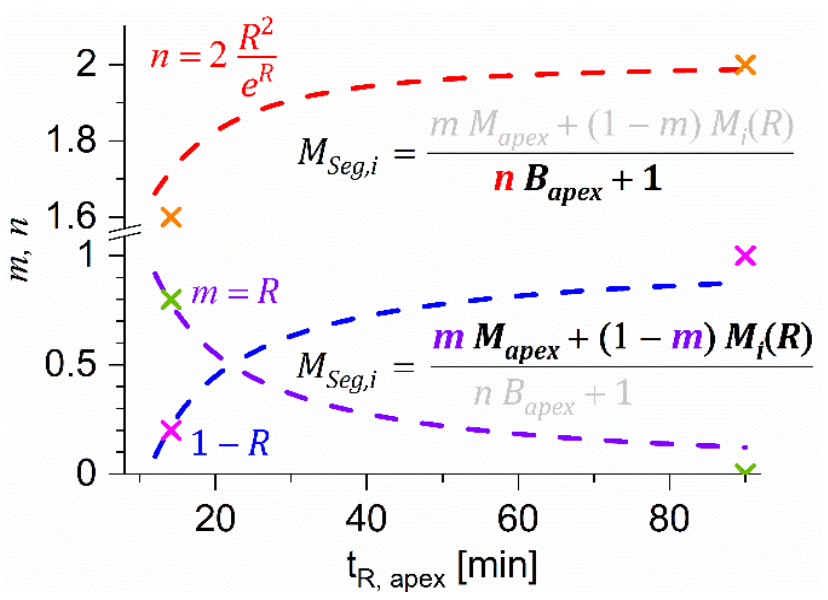

in good agreement to $L C B_{i}\left(M_{i, H T-S E C-D 4}\right)$, interpolated to $M_{i, \text { ThFFF }}$.

Figure S12. The development of a mathematical expression for the correction factor $m$ in the numerator term and $n$ in the denominator term. The dashed lines show the graphs of the equations for $m$ and $n$ matching the empirically found values as boundaries, symbolized by crosses.

Derived function containing the correction for low retention with $R_{\text {apex }}$ as independent variable:

$$
M_{\text {Seg }, i}(R)=\frac{R_{\text {apex }} \cdot M_{\text {apex }}+\left(1-R_{\text {apex }}\right) M_{i}(R)}{\left(2-\frac{R^{2}}{e^{R}}\right) B_{\text {apex }}+1}
$$
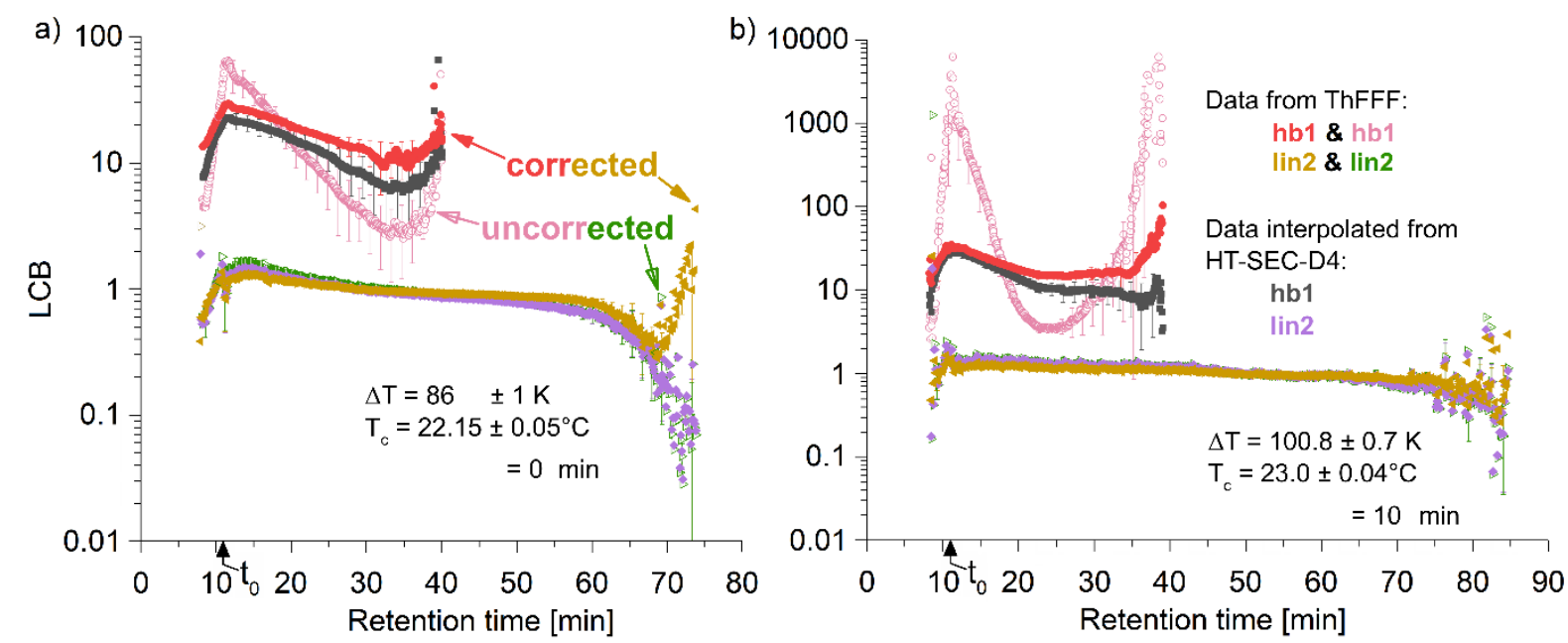

Figure S13. Superimposed data of $L C B_{i}\left[g\left(g^{\prime \prime}, t_{R}\right)\right]$, calculated for the entire fractogram of the hyperbranched sample and of the linear sample, separated without stop-flow and $\Delta \mathrm{T}=85 \mathrm{~K}$ (a) and with stop-flow of $\tau=10 \mathrm{~min} \Delta \mathrm{T}=$ $100 \mathrm{~K}(\mathrm{~b})$, calculated without correction of $M_{\text {Seg,i }}$ (pink and green) and with correction (red and yellow). 


\section{Cumulative and differential weight distributions of $L C B$ and $g$ "}
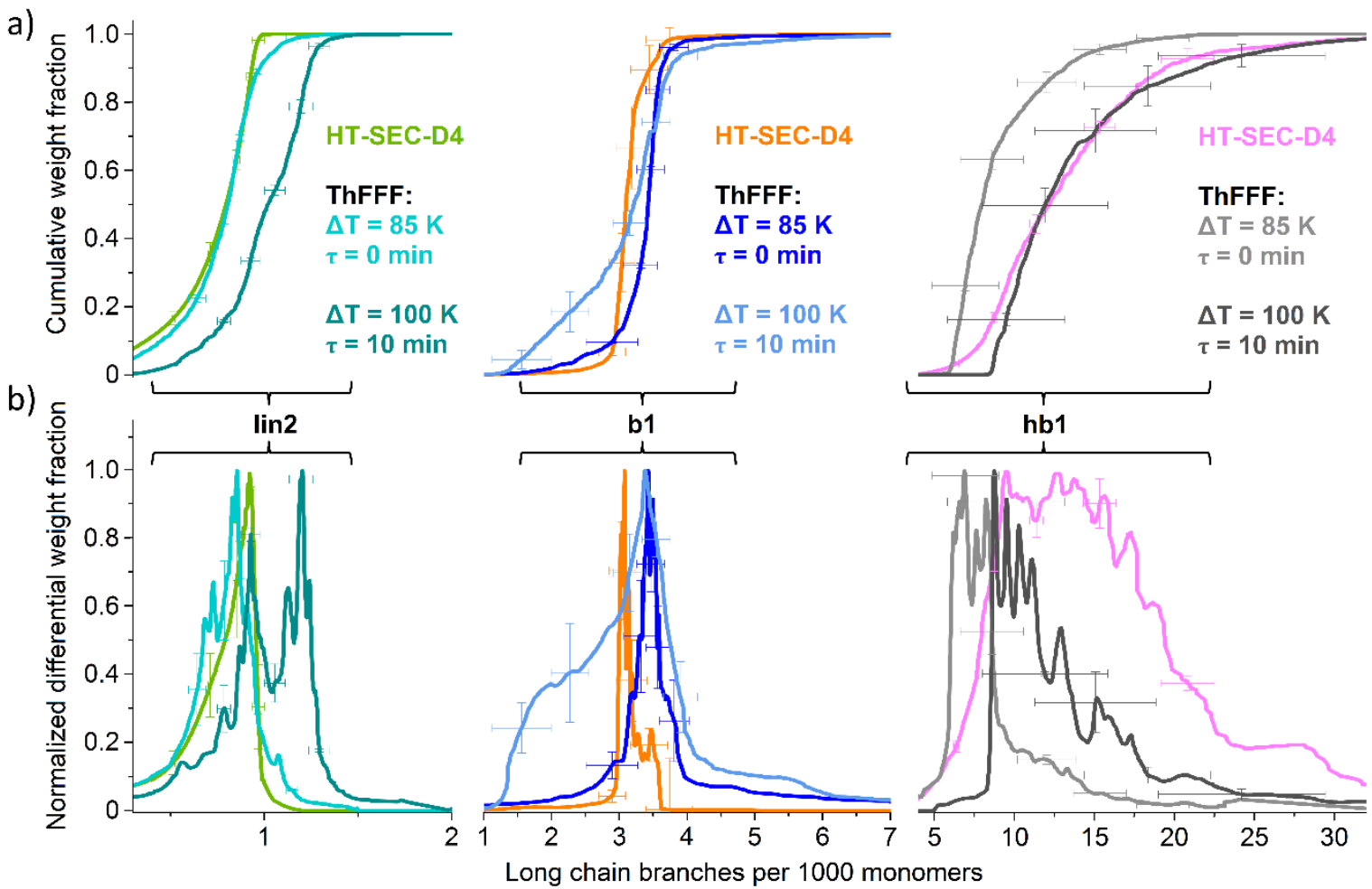

Figure S14. Superimposed cumulative weight (a) and normalized differential weight distributions (b) of $L C B$ of three cwPE samples with different topology as shown in Fig. 7 in the main article.
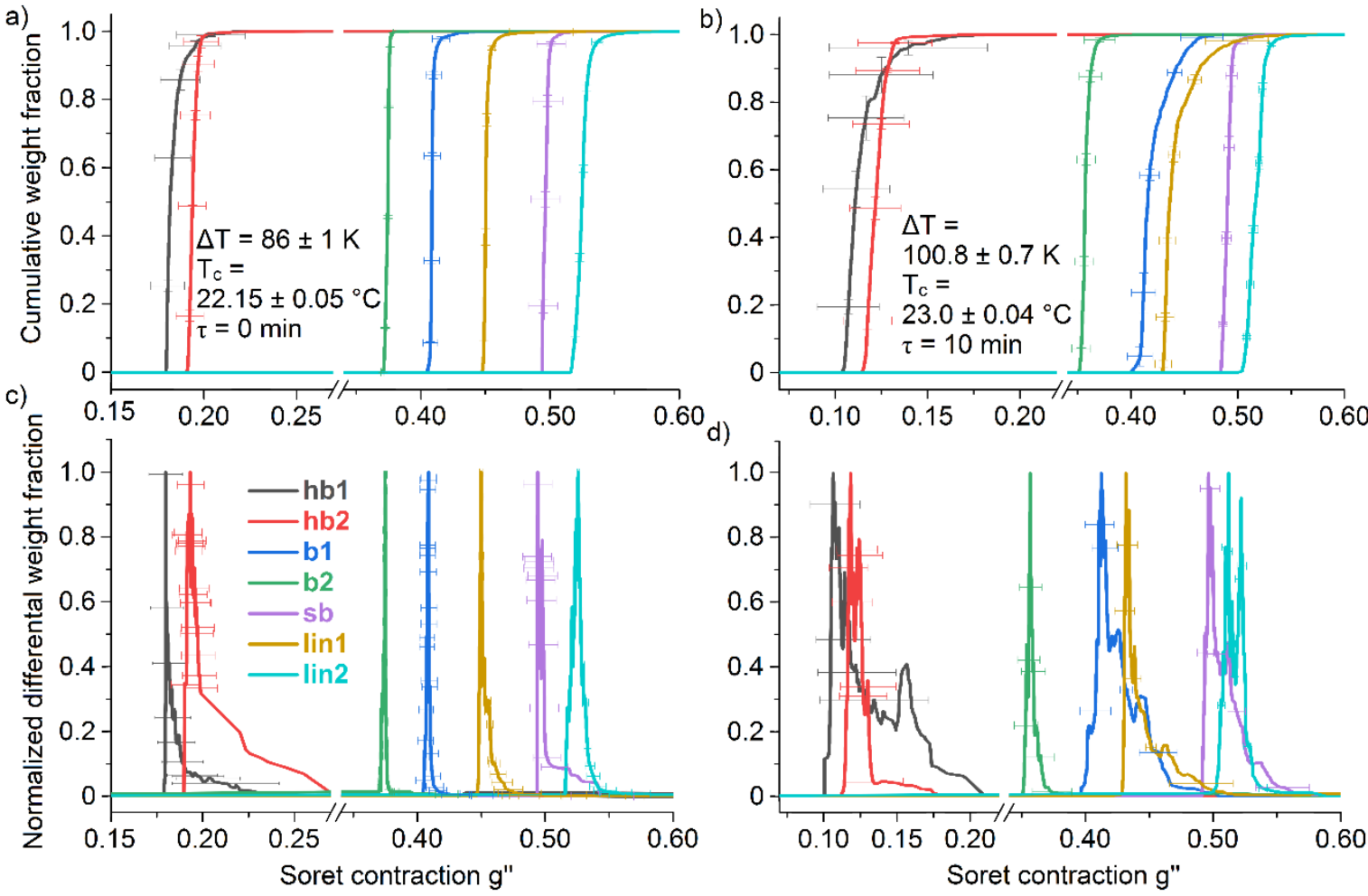

Figure S15. Superimposed cumulative weight (a) and normalized differential weight (b) distributions of $g^{\prime \prime}$ calculated for all seven cwPE samples shown in Fig. 8 of the main article. The differential weight distribution analysis derived from the fractograms indicate, that stop-flow is not needed in order to improve the branching analysis. Avoiding stop-flow can even reduce other distorting influences, ${ }^{17}$ which appear by a long stop-flow time. 

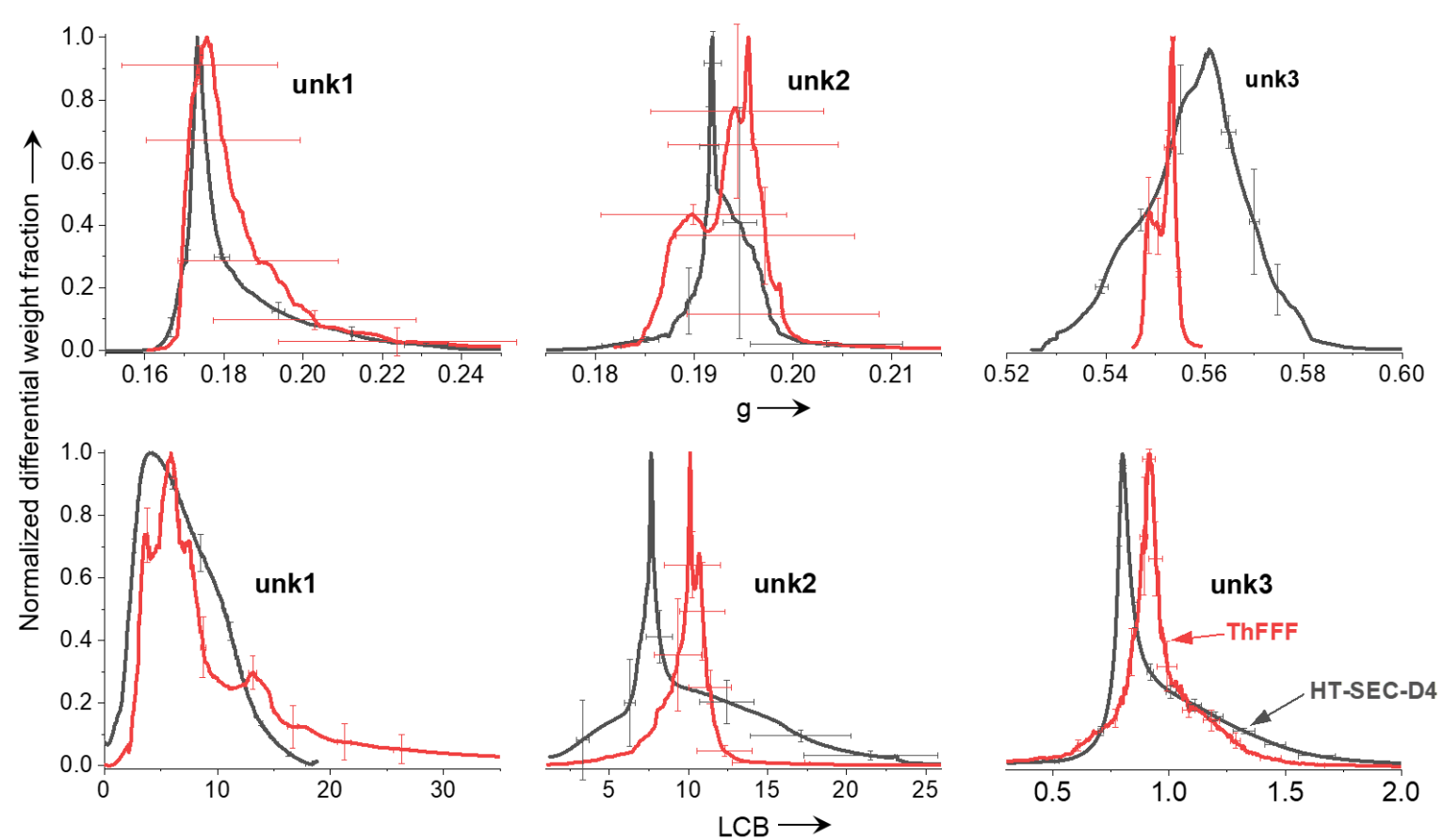

Figure S16. Superimposed normalized differential weight distributions of $\mathrm{g}$ and $L C B$ of three different unknown cwPE samples, analyzed by HT-SEC-D4 (black color) and by ThFFF with the new approach (red color) as given in Eqs. (9) till (13) of the main article. The samples were synthesized with the same synthesis procedure and catalyst within the pressure and temperature limits like the samples hb1 to lin2 as described above. The ThFFF separation was done for unk 1 and unk 2 with $\Delta \mathrm{T}=100.9 \pm 0.8 \mathrm{~K}, \mathrm{~T}_{\mathrm{c}}=22.98 \pm 0.05{ }^{\circ} \mathrm{C}$ and for unk3 with $\Delta \mathrm{T}=$ $84.2 \pm 0.8 \mathrm{~K}, \mathrm{~T}_{\mathrm{c}}=22.07 \pm 0.04{ }^{\circ} \mathrm{C}$. The ThFFF experiments of all unknown samples were performed with a flow rate of $0.2 \mathrm{ml} \mathrm{min}^{-1}$ and $\tau=0 \mathrm{~min}$.

Table S6. Average characterization results of the unknown cwPE samples found by HT-SEC-D4 and ThFFF. The results of $t_{R}, g\left(g^{\prime \prime}\right)$ and $L C B\left[g\left(g^{\prime \prime}\right)\right]$ were generated from the dRI peak apex data.

\begin{tabular}{c|ccccc|cccc} 
& \multicolumn{5}{|c}{ ThFFF } & \multicolumn{4}{c}{ HT-SEC-D4 } \\
Sample & $\begin{array}{c}M_{w} / \\
\mathrm{kg} \mathrm{mol}^{-1}\end{array}$ & $D$ & $t_{R} / \mathrm{min}$ & $g\left(g^{\prime \prime}\right)$ & $L C B\left[g\left(g^{\prime \prime}\right)\right]$ & $\begin{array}{c}M_{w} / \\
\mathrm{kg} \mathrm{mol}^{-1}\end{array}$ & $\oplus$ & $g_{z}$ & $L C B_{w}$ \\
\hline unk1 & $299 \pm 11$ & 1.13 & $13.9 \pm 0.4$ & $0.17 \pm 0.02$ & $9 \pm 3$ & $413 \pm 3$ & 1.63 & $0.20 \pm 0.01$ & $13.0 \pm 0.7$ \\
unk2 & $263 \pm 8$ & 1.03 & $14.0 \pm 0.2$ & $0.19 \pm 0.01$ & $14 \pm 4$ & $394 \pm 1$ & 1.69 & $0.21 \pm 0.01$ & $13.7 \pm 0.5$ \\
unk3 & $288 \pm 16$ & 1.07 & $32.8 \pm 0.6$ & $0.55 \pm 0.01$ & $1.1 \pm 0.1$ & $322 \pm 2$ & 1.08 & $0.560 \pm 0.004$ & $0.79 \pm 0.03$ \\
\hline
\end{tabular}

\section{Uncertainties and errors}

Systematic errors

$T, T_{c}$
Channel dimensions

$\pm(0.3+0.005 \mathrm{~T})\left[\mathrm{T}\right.$ in $\left.{ }^{\circ} \mathrm{C}\right]$

Flow rate

height $\pm 4 \mu \mathrm{m}$, width $\pm 0.05 \mathrm{~mm}$

Time

$\pm 1 \%$

$\Delta \lambda$

data collection interval 0.5 seconds $\approx \pm 0.1 \%$ [Ref. ${ }^{14}$ ]

$\frac{\Delta t_{0}}{t_{0}}=\left[\left(\frac{\Delta h}{h}\right)^{2}+\left(\frac{\Delta w}{h}\right)^{2}+\left(\frac{\Delta \dot{V}}{\dot{V}}\right)^{2}\right]^{0.5}+0.83 \% \approx 3 \%$

$\lambda=\left(K_{0}+K_{1} \cdot \sqrt[3]{R}+K_{2} \cdot \sqrt[3]{R}^{2}+K_{3} \cdot \sqrt[3]{R}^{3}+K_{4} \cdot \sqrt[3]{R}^{4}+K_{5} \cdot \sqrt[3]{R}^{5}+K_{6} \cdot \sqrt[3]{R}^{6}+K_{7} \cdot \sqrt[3]{R}^{7}\right)^{-1}=[f(R, v)]^{-1}$

$\Delta \lambda=\left|\left(\frac{\partial \lambda}{\partial R}\right)_{v}\right||\Delta R|+\left|\left(\frac{\partial \lambda}{\partial v}\right)_{R}\right||\Delta v|+0.001 \lambda=\frac{f^{-1}(R)_{v}}{[f(R, v)]^{2}} \Delta R+\frac{f^{-1}(v)_{R}}{[f(R, v)]^{2}} \Delta v+0.001 \lambda$ 
$\frac{f^{-1}(R)_{v}}{[f(R, v)]^{2}} \Delta R=\frac{K_{1} \cdot \frac{1}{3} R^{-\frac{2}{3}}+K_{2} \cdot \frac{2}{3} R^{-\frac{1}{3}}+K_{3}+\frac{4}{3} K_{4} \cdot R^{\frac{1}{3}}+\frac{5}{3} K_{5} \cdot R^{\frac{2}{3}}+2 K_{6} \cdot R+\frac{7}{3} K_{7} \cdot R^{\frac{4}{3}}}{\left(K_{0}+K_{1} \cdot \sqrt[3]{R}+K_{2} \cdot \sqrt[3]{R}^{2}+K_{3} \cdot \sqrt[3]{R}^{3}+K_{4} \cdot \sqrt[3]{R}^{4}+K_{5} \cdot \sqrt[3]{R}^{5}+K_{6} \cdot \sqrt[3]{R}+K_{7} \cdot \sqrt[3]{R}^{7}\right)^{2}}\left\{\left[\left(\frac{\Delta t_{R}}{t_{R}}\right)^{2}+\left(\frac{\Delta t_{0}}{t_{0}}\right)^{2}\right]^{0.5} \cdot \frac{t_{0}}{t_{R}}\right\}$

$\frac{f^{-1}(v)_{R}}{[f(R, v)]^{2}} \Delta v=\frac{K_{0}^{\prime}+K_{1}^{\prime} \cdot \sqrt[3]{R}+K_{2}^{\prime} \cdot \sqrt[3]{R}^{2}+K_{3}^{\prime} \cdot R+K_{4}^{\prime} \cdot \sqrt[3]{R}+K_{5}^{\prime} \cdot \sqrt[3]{R}^{5}+K_{6}^{\prime} \cdot R^{2}+K_{7}^{\prime} \cdot \sqrt[3]{R}^{7}}{\left(K_{0}+K_{1} \cdot \sqrt[3]{R}+K_{2} \cdot \sqrt[3]{R}^{2}+K_{3} \cdot \sqrt[3]{R}^{3}+K_{4} \cdot \sqrt[3]{R}^{4}+K_{5} \cdot \sqrt[3]{R}^{5}+K_{6} \cdot \sqrt[3]{R}^{6}+K_{7} \cdot \sqrt[3]{R}^{7}\right)^{2}} \Delta v$

with $K_{x}^{\prime}=0+(\ldots)_{1}+2(\ldots)_{2} \cdot v+3(\ldots)_{3} \cdot v^{2}+4(\ldots)_{4} \cdot v^{3} ; \quad \frac{\Delta v}{v}=\left[\left(\frac{\Delta(\Delta \mathrm{T})}{\Delta \mathrm{T}}\right)^{2}+\left(\frac{\Delta \mathrm{T}_{c}}{\mathrm{~T}_{c}}\right)^{2}\right]^{0.5}$

and $\frac{\Delta(\Delta T)}{\Delta T}=\frac{\Delta(\Delta \mathrm{T})_{\text {random }}}{\Delta T}+\left[\left(\frac{0.3+0.005 T_{\text {hot }}}{T_{\text {hot }}}\right)^{2}+\left(\frac{0.3+0.005 T_{C}}{T_{C}}\right)^{2}\right]^{0.5}$

Uncertainty calculations exemplarily for lin2 (see Table 1 in the main article):

$\frac{f^{-1}(R)_{v}}{[f(R, v)]^{2}} \Delta R=0.00393381$ with $t_{R}=53.34 \pm 3.3 \mathrm{~min} ; t_{0}=11.035 \pm 0.33 \mathrm{~min}$

$\frac{f^{-1}(v)_{R}}{[f(R, v)]^{2}} \Delta v=0.00077567$ with $v=-0.3762469$

$\frac{\Delta(\Delta T)}{\Delta T}=\frac{0.97 \mathrm{~K}}{99.02 \mathrm{~K}}+\left[\left(\frac{0.3+0.005 \cdot 121.9^{\circ} \mathrm{C}}{121.9^{\circ} \mathrm{C}}\right)^{2}+\left(\frac{0.3+0.005 \cdot 22.88^{\circ} \mathrm{C}}{22.88^{\circ} \mathrm{C}}\right)^{2}\right]^{0.5}=\underline{0.0294278}$

$\frac{\Delta v}{v}=\left[(0.0294278)^{2}+(0.002325)^{2}\right]^{0.5}=\underline{0.0295195}$

$\Delta \lambda=0.00393381+0.00077567+0.001 \cdot 0.05557648=\underline{0.00478181}$

$\frac{\Delta D}{D}=\left[\left(\frac{\Delta D}{D}\right)_{D L S}^{2}+\left(\frac{\Delta D(T)}{D(T)}\right)_{F i t}{ }^{2}\right]^{0.5}=\left[(0.009562)_{D L S}{ }^{2}+(0.0047242)_{F i t}{ }^{2}\right]^{0.5}=\underline{0.010665}$

$S_{T}=\frac{1}{\lambda \Delta T}=\frac{1}{0.05557 \cdot 99.02 K} \quad \Delta S_{T}=\left[\frac{\Delta \lambda}{\lambda}+\frac{\Delta(\Delta T)}{\Delta T}\right] \cdot S_{T}=\left(\frac{0.00478181}{0.05557}+0.0294278\right) \cdot S_{T}=\underline{0.02098 K^{-1}}$

$D_{T}=\frac{D}{\lambda \Delta T}=\frac{1.3738 \cdot 10^{-7} \frac{\mathrm{cm}^{2}}{\mathrm{~s}}}{0.0555765 \cdot 99.02 \mathrm{~K}}$

$\Delta D_{T}=\left[\frac{\Delta D}{D}+\frac{\Delta \lambda}{\lambda}+\frac{\Delta(\Delta T)}{\Delta \mathrm{T}}\right] \cdot D_{T}=\underline{3.1488 \times 10^{-9} \frac{\mathrm{cm}^{2}}{\mathrm{sK}}}$

$D_{T}=\underline{\underline{(2.5 \pm 0.3) \times 10^{-8} \frac{\mathrm{cm}^{2}}{\mathrm{sK}}}} \quad S_{T}=\underline{\underline{(0.18 \pm 0.02) K^{-1}}}$ 


\section{References:}

(1) Mundil, R.; Hermanová, S.; Peschel, M.; Lederer, A.; Merna, J. On the Topology of Highly Branched Polyethylenes Prepared by Amine-imine Nickel and Palladium Complexes: The Effect of Ortho-Aryl Substituents. Polym. Int. 2018, 67 (7), 946-956.

(2) Plüschke, L.; Mundil, R.; Sokolohorskyj, A.; Merna, J.; Sommer, J.-U.; Lederer, A. High Temperature Quadruple-Detector Size Exclusion Chromatography for Topological Characterization of Polyethylene. Anal. Chem. 2018, 90 (10), 6178-6186.

(3) Dockhorn, R.; Plüschke, L.; Geisler, M.; Zessin, J.; Lindner, P.; Mundil, R.; Merna, J.; Sommer, J.-U.; Lederer, A. Polyolefins Formed by Chain Walking Catalysis-A Matter of Branching Density Only? $J$. Am. Chem. Soc. 2019, 141 (39), 15586-15596.

(4) Johnson, L. K.; Killian, C. M.; Brookhart, M. New Pd(II)- and Ni(II)-Based Catalysts for Polymerization of Ethylene and .Alpha.-Olefins. J. Am. Chem. Soc. 1995, 117 (23), 6414-6415.

(5) Guan, Z. Chain Walking: A New Strategy to Control Polymer Topology. Science (80-. ). 1999, 283 (5410), 2059-2062.

(6) Koppel, D. E. Analysis of Macromolecular Polydispersity in Intensity Correlation Spectroscopy: The Method of Cumulants. J. Chem. Phys. 1972, 57 (11), 4814-4820.

(7) Wyatt, P. J. Light Scattering and the Absolute Characterization of Macromolecules. Anal. Chim. Acta 1993, 272 (1), 1-40.

(8) Müller, G.; Arndt, K. F. Polymercharakterisierung; Carl Hanser Verlag: München, Wien, Wien, 1996, 124-142.

(9) Lederer, A.; Burchard, W. Hyperbranched Polymers; Polymer Chemistry Series; The Royal Society of Chemistry, 2015.

(10) Flory, P. J. Principles of Polymer Chemistry; Cornell University Press: Ithaca, London, London, 1953, 283-303.

(11) Einstein, A. Über Die von Der Molekularkinetischen Theorie Der Wärme Geforderte Bewegung von in Ruhenden Flüssigkeiten Suspendierten Teilchen. Ann. Phys. 1905, 322 (8), 549-560.

(12) Lederer, A.; Hartmann, T.; Komber, H. Sphere-Like Fourth Generation Pseudo-Dendrimers with a Hyperbranched Core. Macromol. Rapid Commun. 2012, 33 (17), 1440-1444.

(13) Burchard, W. Solution Properties of Branched Macromolecules. In Branched Polymers II; Roovers, J., Ed.; Springer Berlin Heidelberg: Berlin, Heidelberg, Heidelberg, 1999; 113-194.

(14) Belgaied, J. E.; Hoyos, M.; Martin, M. Velocity Profiles in Thermal Field-Flow Fractionation. $J$. Chromatogr. A 1994, 678 (1), 85-96.

(15) Schimpf, M. E.; Caldwell, K.; Giddings, J. C. Field-Flow Fractionation Handbook; John Wiley \& Sons, Inc., 2000, 31-48.

(16) Martin, M.; Williams, P. S. Theoretical Basis of Field-Flow Fractionation. In Theoretical Advancement in Chromatography and Related Separation Techniques; Dondi, F., Guiochon, G., Eds.; Springer Netherlands: Dordrecht, 1992; 513-580.

(17) Smith, L. K.; Myers, M. N.; Giddings, J. C. Peak Broadening Factors in Thermal Field-Flow Fractionation. Anal. Chem. 1977, 49 (12), 1750-1756. 